\title{
DRONE UNTUK PERCEPATAN PEMETAAN BIDANG TANAH
}

\section{Budi Utomo}

Masuk: 09122017 / Diterima: 30122017 / Dipublikasi: 31122017

(C) 2017 Fakultas Hukum dan IImu Sosial UNDIKSHA dan IGI

\begin{abstract}
Since 2016 the government has accelerated the registration of land systematically complete until in 2025 the whole plot of land in Indonesia registered. In 2018 alone the government is targeting 7 million fields, and 2019 is targeting 9 million. To achieve these targets is required technology that can overcome this. Drone, better known as Unmanned Aerial Vehicle (UAV) or unmanned aircraft technology as a solution for mapping of land with a large target, time and area flexibility desired shooting, and detailed shooting spatial resolution results as well as a relatively cheaper cost than the recording price with satellite. This study aims: to determine the level of accuracy of the drone generated mapping, and to compare the price of aerial photography produced by the drone with the image produced by the satellite. This research uses qualitative method. Data were obtained from the study literature. After the data collected it will be done data analysis with three stages, namely; Reduction, Display, and Conclution. The results of this study shows that the use of drones for the acceleration of land mapping is the right choice because the drone shots have spatial resolution which is so high that it complies with ground mapping rules and the price is cheap.
\end{abstract}

Key words: Drone, Mapping, Plot of Land

Abstrak Sejak tahun 2016 pemerintah melaksanakan percepatan pendaftaran tanah sistematik lengkap hingga pada tahun 2025 seluruh bidang tanah di Indonesia telah terdaftar. Pada tahun 2018 saja pemerintah menargetkan 7 juta bidang, dan tahun 2019 menargetkan 9 juta. Untuk mencapai target tersebut diperlukan teknologi yang bisa mengatasi hal tersebut. Drone, yang lebih dikenal Unmanned Aerial Vehicle (UAV) atau teknologi pesawat tanpa awak sebagai solusi untuk pemetaan tanah dengan target yang banyak, feksibilitas waktu dan areal pemotretan yang diinginkan, dan hasil pemotretan resolusi spasial yang detil serta biaya yang relatif lebih murah dibandingkan harga perekaman dengan satelit. Penelitian ini bertujuan: untuk mengetahui tingkat ketelitian pemetaan yang dihasilkan drone, dan untuk mengetahui perbandingkan harga foto udara yang dihasilkan oleh drone dengan citra yang dihasilkan oleh satelit. Penelitian ini menggunakan metode kualitatif. Data didapatkan dari studi literatur. Setelah data terkumpul maka akan dilakukan analisis data dengan tiga tahapan, yaitu; Reduction, Display, dan Conclution. Hasil penelitian ini menunjukkan bahwa penggunaan drone untuk percepatan pemetaan tanah adalah pilihan yang tepat karena hasil pemotretan drone punya resolusi spasial yang tinggi sehingga sesuai dengan aturan pemetaan bidang tanah dan harganya murah.

Kata kunci: Drone, Pemetaan, Bidang Tanah

\section{Pendahuluan}

Kebutuhan pengukuran dan pemetaan bidang tanah di Indonesia masih sangat tinggi dimana masih banyak bidang-bidang tanah yang belum terpetakan. Sejak tahun 2016 pemerintah melaksanakan percepatan pendaftaran tanah sistematik lengkap 
hingga pada tahun 2025 seluruh bidang tanah di Indonesia telah terdaftar. Pada tahun 2018 saja pemerintah menargetkan 7 juta bidang, dan tahun 2019 menargetkan 9 juta (Permen ATR/BPN No. 25 Tahun 2015). Untuk itu dibutuhkan metode pengukuran dan pemetaan bidang tanah yang efektif dan efisien untuk menunjang terlaksananya pemetaan bidang tanah tersebut.

Pengukuran dan pemetaan bidang tanah yang efektif dalam pengambilan data yang akurat sesuai posisi dan sesuai dengan ketentuan pemetaan, dan efisien dalam biaya maupun waktu pelaksanaan pengukuran dan pemetaan bidang tanah. Akan tetapi Kementerian ATR/BPN masih menyisakan permasalahan masa lalu terkait dengan Infrastruktur Keagrarian yang sampai saat ini belum terselesaikan, yaitu terdapat 24 (dua puluh empat) juta bidang tanah dari 44 (empat puluh empat) bidang tanah terdaftar (lebih dari $50 \%$ ) bidang tanah terdaftar yang belum dipetakan di Peta Pendaftaran (BPN,2016) dalam Kusmiarto (2017).

Salah satu cara yang dapat dilakukan pengambilan data efektif dan efisien adalah dengan menggunakan drone yang biasa disebut pesawat tanpa awak (Unmanned Aerial Vehicle $(\mathrm{UAV})$ ). Drone adalah wahana yang dilengkapi sistem pengendali terbang melalui gelombang, navigasi presisi (Ground Positioning System (GPS)), dan elektronik kontrol penerbangan sehingga mampu terbang sesuai perencanaan terbang (autopilot). Drone ini memungkinkan untuk melakukan pelacakan posisi dan orientasi dari sensor yang diimplementasikan dalam sistem lokal atau koordinat global (Eisenbeiss, 2009). Dengan drone sendiri mengefisienkan waktu karena dapat memiliki citra suatu wilayah kapan pun kita mau tldak terganung waktu seperti citra satelit waktu perekamannya yang sudah diatur (proide ulang perekaman daerah yang sama).

Drone biasanya juga dilengkapi dengan peralatan kamera resolusi tinggi dapat melakukan pemotretan foto udara. Penggunaan drone menghasilkan gambar/citra dengan resosuli spasial yang besar, tidak terkendala awan, karena pengoperasiaannya pada ketinggian di bawah awan. Melalui drone, skala kedetailan data menjadi sangat tinggi dan proses pengumpulan datanya menjadi lebih mudah (Zaco. et al, 2014) Drone merupakan pesawat tanpa pilot. Pesawat ini dikendalikan secara otomatis melalui program komputer yang dirancang (Bahar, 2016). Drone petama dikembangkan untuk kepentingan militer. Drone digunakan sebagai pengintai musuh dan mengurangi korban manusia (pilot). Penggaunaan drone untuk misi militer sejak perang dunia petama dan perang dunia kedua sebagai prototibe (Ahmad, 2011). Penggunaan drone sekarang lebih banyak tidak hanya militer saja, aplikasi drone untuk pertanian (Candiago, et.al. 2015), aplikasi drone untuk pemetaan vegetasi perkotaan (Feng, et.al. 2015), aplikasi drone untuk tanah longsor (Fernández, et.al. 2016), aplikasi drone untuk tutupan lahan (Hassan, et.al. 2011).

Menurut Bahar tahun 2016, klasifikasi drone atas dasar sayapnya dibagi menjadi dua, yaitu multicopter 
dan fixed wing. Fixed wing memiliki bentuk seperti pesawat terbang biasa yang dilengkapi sistem sayap. Sedangkan multicopter yaitu jenis drone yang memanfaatkan putaran baling-baling untuk terbang. Multicopter dibagi lagi menjadi dua yaitu singlerotor dan multi-rotor. Tipe single-rotor berbentuk seperti helikopter menggunakan baling-baling tunggal, sedangkan multi-rotor menggunakan 3 sampai 8 baling-baling. Klasifikasi drone secara internasional yang di kutip oleh Ahmad (2011) dapat dilihat pada tabel 1 di bawah ini.

Tabel 1. Kategori UAV Internasional

\begin{tabular}{lllllll}
\hline No & Kategori & Berat $(\mathrm{Kg})$ & $\begin{array}{l}\text { Jangkauan } \\
(\mathrm{Km})\end{array}$ & $\begin{array}{l}\text { Tinggi } \\
\text { terbang }(\mathrm{m})\end{array}$ & $\begin{array}{l}\text { Daya } \\
(\text { jam })\end{array}$ & Tahan \\
\hline 1 & Mikro & $<5$ & $<10$ & 250 & 1 \\
2 & mini & $<250 / 30 / 150$ & $<10$ & $150 / 250 / 300$ & $<2$ \\
3 & $\begin{array}{l}\text { Jangkauan } \\
\text { sempit }\end{array}$ & $25-150$ & $10-30$ & 3000 & $2-4$ \\
4 & $\begin{array}{l}\text { Jangkauan } \\
\text { menengah }\end{array}$ & $50-250$ & $30-70$ & 3000 & $3-6$ \\
5 & $\begin{array}{l}\text { Jangkauan jauh } \\
\text { Sumber: Ahmad, 2011 }\end{array}$ & $>70$ & $>3000$ & $>6$ \\
\hline
\end{tabular}

Pengendalian pengoprasian drone di Indonesia tidak boleh sembarangan. Saat ini pengendalian pengoprasian drone telah diatur dalam Peraturan Menteri Perhubungan No 90 Tahun 2015 tentang Pengendalian Pengoprasian Pesawat Udara Tanpa Awak Di Ruang Udara Dilayani di Indonesia. Dalam rangka keselamatan oprasional penerbangan di ruang udara, pengendalian pengoprasian pesawat udara tanpa awak tidak boleh beroprasi dikawasan sebagai berikut.

- Kawasan udara terlarang

- Kawasan udara terbatas

- Kawasan keselamatan oprasi penerbangan (KOP) suatu Bandar udara.

Sebuah pesawat udara tanpa awak pada ruang udara kurang dari $500 \mathrm{ft}$ (150 meter). Dalam kondisi khusus untuk kepentingan patrol batas wilayah negara, patrol wilayah laut negara, pantauan cuaca, pengamataan aktivitas hewan dan tumbuhan di taman nasional, survai dan pemetaan, sebuah pesawat udara tanpa awak boleh dioprasikan di ketinggian dari $500 \mathrm{ft}$ (150 meter) dengan izin yang diberikan Direktur Jendral Perhubungan Udara.

Peta sebagai gambaran sebagian atau seluruh wilayah permukaan bumi dengan berbagai kenampakan pada suatu bidang datar yang diperkecil dengan menggunakan skala tertentu (Setyowati, et al. 2014). Sedangkan pemetaan adalah proses, cara, perbuatan membuat peta.

Pemetaan bidang tanah merupakan bagian dari pendaftaran tanah secara sistematis lengkap. Pemetaan bidang tanah adalah kegiatan menggambarkan hasil pengukuran bidang tanah secara sistematik maupun sporadik dengan suatu metode tertentu pada media tertentu seperti lembaran kertas, 
drafting film atau media lainnya sehingga letak danukuran bidang tanahnya dapat diketahui dari media tempat pemetaan bidang tanah tersebut. Dalam pemetaan bidang tanah menurut Peraturan Menteri Negara Agraria/Kepala Badan Pertanahan Nasional No.3 tahun 1997 memerlukan peta dasar berupa:

- Peta foto udara (baik dari wahana pesawat udara atau Unmanned Aerial

- Vehicle (UAV)/drone),

- Peta Citra satelit resolusi tinggi (CSRT) atau

- Peta garis

Peta dasar pendaftaran dibuat dengan skala 1:1.000 atau lebih besar untuk daerah pemukiman, 1:2.500 atau lebih besar untuk daerah pertanian dan 1:10.000 untuk daerah perkebunan besar. Untuk mendapatkan peta yang baik maka diperlukan sumber pemuatan peta dengan ketelitian yang tinggi. Spesifikasi Peta Dasa yang dapat digunakan sebagai peta kerja menurut Direktorat Jenderal Infrastruktur Keagrariaan Kementerian Agraria dan Tata Ruang/Badan Pertanahan Nasional tahun 2016 ketelitian geometrik dari peta kerja yang digunakan adalah:

1. Daerah pemukiman, daerah komersial dan/atau daerah industri, ketelitian yang digunakan adalah $0,3 \mathrm{~mm} \times$ skala peta;

2. Daerah non-pemukiman, daerah non-komersial dan/atau daerah nonindustri, ketelitain yang digunakan adalah $0,5 \mathrm{~mm} \times$ skala peta.

Sedangkan ketelitian geometris menurut Peraturan Kepala Badan Informasi Geospasial Nomor 15 Tahun 2014 Tentang Pedoman Teknis Ketelitian Peta Dasar, menentukan standar ketelitian geometri Peta RBI yang dihasilkan tertera pada tabel 2 di bawah ini.

Tabel 2. Ketelitian Geometri Peta RBI

\begin{tabular}{|c|c|c|c|c|c|c|c|c|}
\hline \multirow[b]{3}{*}{ No. } & \multirow[b]{3}{*}{ Skala } & \multirow{3}{*}{$\begin{array}{c}\text { Interval } \\
\text { kontur } \\
\text { (m) }\end{array}$} & \multicolumn{6}{|c|}{ Ketelitian Peta RBI } \\
\hline & & & \multicolumn{2}{|c|}{ Kelas 1} & \multicolumn{2}{|c|}{ Kelas 2} & \multicolumn{2}{|c|}{ Kelas 3} \\
\hline & & & $\begin{array}{l}\text { Horizontal } \\
\text { (CE90 } \\
\text { dalam m) }\end{array}$ & $\begin{array}{l}\text { Vertikal } \\
\text { (LE90 } \\
\text { dalam m) }\end{array}$ & $\begin{array}{l}\text { Horizontal } \\
\text { (CE90 } \\
\text { dalam m) }\end{array}$ & $\begin{array}{l}\text { Vertikal } \\
\text { (LE90 } \\
\text { dalam m) }\end{array}$ & $\begin{array}{l}\text { Horizontal } \\
\text { (CE90 } \\
\text { dalam m) }\end{array}$ & $\begin{array}{l}\text { Vertikal } \\
\text { (LE90 } \\
\text { dalam m) }\end{array}$ \\
\hline 1. & $1: 1.000 .000$ & 400 & 200 & 200 & 300 & $\overline{300,00}$ & $\overline{500}$ & $\overline{500,00}$ \\
\hline 2. & $1: 500.000$ & 200 & 100 & 100 & 150 & 150,00 & 250 & 250,00 \\
\hline 3. & $1: 250.000$ & 100 & 50 & 50 & $\overline{75}$ & 75,00 & 125 & 125,00 \\
\hline 4. & $1: 100.000$ & 40 & 20 & 20 & 30 & 30,00 & $\overline{50}$ & $\overline{50,00}$ \\
\hline 5. & $1: 50.000$ & 20 & 10 & 10 & $\overline{15}$ & 15,00 & 25 & 25,00 \\
\hline 6. & $1: 25.000$ & 10 & 5 & 5 & 7,5 & 7,50 & 12,5 & 12,50 \\
\hline 7 . & $1: 10.000$ & 4 & 2 & 2 & 3 & 3,00 & 5 & 5,00 \\
\hline 8. & $1: 5.000$ & 2 & $\overline{1}$ & $\overline{1}$ & 1,5 & 1,50 & 2,5 & 2,50 \\
\hline 9. & $1: 2.500$ & $\overline{1}$ & 0,5 & 0,5 & 0,75 & 0,75 & 1,25 & 1,25 \\
\hline 10. & $1: 1.000$ & 0,4 & 0,2 & 0,2 & 0,3 & 0,30 & 0,5 & 0,50 \\
\hline
\end{tabular}

Sumber: Peraturan Kepala Badan Informasi Geospasial Nomor 15 Tahun 2014. 
Nilai ketelitian di setiap kelas diperoleh melalui ketentuan seperti tertera pada tabel 3 di bawah ini.

Tabel 3. Ketentuan Ketelitian Geometri Peta RBI Berdasarkan Kelas

\begin{tabular}{|l|l|l|l|}
\hline Ketelitian & \multicolumn{1}{|c|}{ Kelas 1 } & \multicolumn{1}{c|}{ Kelas 2 } & \multicolumn{1}{c|}{ Kelas 3 } \\
\hline Horizontal & $0,2 \mathrm{~mm} \times$ bilangan skala & $0,3 \mathrm{~mm} \times$ bilangan skala & $0,5 \mathrm{~mm} \times$ bilangan skala \\
\hline Vertikal & $0,5 \mathrm{x}$ interval kontur & $1,5 \mathrm{x}$ ketelitian kelas 1 & $2,5 \mathrm{x}$ ketelitian kelas 1 \\
\hline
\end{tabular}

Sumber: Peraturan Kepala Badan Informasi Geospasial Nomor 15 Tahun 2014

Nilai ketelitian posisi peta dasar pada Tabel 2 adalah nilai CE90 untuk ketelitian horizontal dan LE90 untuk ketelitian vertikal, yang berarti bahwa kesalahan posisi peta dasar tidak melebihi nilai ketelitian tersebut dengan tingkat kepercayaan $90 \%$.

Untuk mempermudah penelitian ini di susun rumusan masalah sebagai berikut ini.

- Bagaimana tingkat ketelitian citra yang dihasilkan drone?.

- Bagaimana perbandingkan harga foto udara yang dihasilkan oleh drone dengan citra yang dihasilkan oleh satelit?

Atas dasar rumusan masalah di atas penelitian ini tujuan untuk:

- Untuk mengetahui tingkat ketelitian pemetaan yang dihasilkan drone.

- Untuk mengetahui perbandingkan harga foto udara yang dihasilkan oleh

- drone dengan citra yang dihasilkan oleh satelit.

\section{Metode}

Penelitian ini menggunakan metode kualitatif. Metode ini peneliti gunakan karena dalam proses penelitian ini pengumpulan datanya dilakukan dengan data sekunder, yaitu langsung diambil dari lapangan secara alami. Data didapatkan dari studi literatur. Setelah data terkumpul maka akan dilakukan analisis data dengan tiga tahapan, yaitu; Reduction, Display, dan Conclution.

\section{Reduction}

Data yang terkumpul dari lapangan dan studi literature kemudian di reduksi. Mereduksi data adalah memilih hal-hal yang penting, memfokuskan hal-hal yang pokok kemudian dicari pola dan inti dari data untuk mendapatkan gambaran penelitian.

\section{Display}

Tahapan display atau penyajian data dilakukan dalam bentuk uraian singkat, tabel, data persentase. Dengan mendisplaykan data, maka akan memudahkan untuk memahami apa yang terjadi, merencanakan kerja selanjutnya berdasarkan tujuan penelitian.

\section{Conclution}

Kesimpulan awal yang dikemukakan masih bersifat sementara, dan akan berubah bila ditemukan bukti-bukti yang kuat yang mendukung pada tahap pengumpulan data berikutnya. Tetapi 
apabila kesimpulan yang dikemukakan pada tahap awal, didukung oleh buktibukti yang valid dan konsisten saat peneliti kembali ke lapangan mengumpulkan data, maka kesimpulan yang dikemukakanmerupakan kesimpulan yang kredibel.

Untuk mendapatkan data yang valid, data yang terdapat di lapangan dan data yang dilaporkan perlu dilakukan keabsahan data. Dalam penelitian ini keabsahan data dilakukan dengan perpanjangan pengamatan, peningkatan ketekunan, dan traingulasi data serta diskusi dengan teman sejawat.

\section{Hasil Dan Pembahasan}

\subsection{Ketelitian citra dihasilkan drone}

Drone yang biasa digunakan sebagai pemetaan umumnya menggunakan DJI Phantom 3 profesional atau spesifikasi setingkatnya atau lebih janggih. Penggunaan drone DJI Phantom 3 profesional diantaranya (Wulan. et al, 2016) dan Adi. et al, (2017). Penggunaan jenis drone ini dengan alasan karena foto yang dihasilkan mempunyai resolusi spasial yang tinggi dan harga relatif terjangkau. Adapun spesifikasi DJI Phantom 3 profesional dapat dilihat pada Tabel 4 di bawah.

Tabel 4. Spesifikasi DJI Phantom 3 Profesional

\begin{tabular}{|c|c|c|}
\hline No & Spesifikasi & Keterangan \\
\hline 1 & Berat & $1280 \mathrm{~g}$ \\
\hline 2 & Maksimum kecepatan terbang & $16 \mathrm{~m} / \mathrm{s}$ (ATTI mode) \\
\hline 3 & Maksimum waktu terbang & 23 menit \\
\hline 4 & $\begin{array}{l}\text { Dilengkapi Sistem penentuan posisi } \\
\text { satelit }\end{array}$ & GPS/GLONASS \\
\hline 5 & Sensor kamera & $\begin{array}{l}\text { Sony Exmor } 1 / 2.3 \text { " CMOS } \\
\text { Effective pixels: } 12.4 \mathrm{M} \text { (total } \\
\text { pixels: } 12.76 \mathrm{M} \text { ) }\end{array}$ \\
\hline 6 & Mode Fotografi & $\begin{array}{l}\text { - Single Shot } \\
\text { - Burst Shooting: } 3 / 5 / 7 \text { frames } \\
\text { - Auto Exposure Bracketing } \\
\text { (AEB): } 3 / 5 \text { bracketed frames } \\
\text { at } 0.7 \text { EV Bias } \\
\text { - Timelapse }\end{array}$ \\
\hline 7 & Format Gambar & JPEG, DNG (RAW) \\
\hline 8 & Format Video & $\begin{array}{l}\text { MP4, MOV (MPEG-4 } \\
\text { AVC/H.264) }\end{array}$ \\
\hline 9 & File duport sistem & $\begin{array}{l}\text { FAT32 ( } \leq 32 \text { GB); exFAT }(>32 \\
\text { GB) }\end{array}$ \\
\hline 10 & Sistem Operasi & $\begin{array}{l}\text { Bisa dioprasikan pada } \\
\text { - iOS } 8.0 \text { or later } \\
\text { - Android 4.1.2 or later }\end{array}$ \\
\hline
\end{tabular}

Sumber: DJI, 2015

Ketelitian citra foto dihasilkan dari drone atau UAV sesuai standar geometri yang dipersyaratkan Perka BIG Nomor 15 Tahun 2014
Tentang Pedoman Teknis Ketelitian Peta Dasar maupun yang dipersyaratkan Peraturan Menteri Negara Agraria/Kepala Badan 
Pertanahan Nasional No.3 tahun 1997 tentang Ketentuan Pelaksanaan Peraturan Pemerintah Nomor 24 Tahun 1997 Tentang Pendaftaran Tanah. Ketelitian citra foto dihasilkan dari drone telah diuji oleh Wulan, et Al (2016), dan Ramadhani, et Al (2015) hasilnya menunjukkan persentase akurasi data UAV keseluruhan sampel rata-rat mencapai 96, 2 \%. Kedua peneliti menggunakan sensor kamera digital dengan resolusi 12 Mega Pixels (MP), walaupun menggunakan menggunakan produk drone berbeda. Pengujian lain dilakukan oleh Adi, et Al (2017) menggunakan juga sensor kamera digital dengan resolusi 12 Mega Pixels hasilnya diuji secara statistic (uji statistika F), Adi dan temantemanya ingin menguji perbedaan hasil pemotretan drone DJI Phantom 3 Professional, dan hasil yang didapatkan tidak terdapat perbedaan ketelitian geometri yang signifikan antara orthofoto yang dihasilkan. Hasil semua hitungan $\mathrm{F}$ atau $\mathrm{F}$ hitung lebih kecil dari nilai $F$ tabel dengan tingkat kepercayaan $90 \%$.

Peta yang dihasilkan menggunakan sensor kamera digital dengan resolusi
12 Mega Pixels skala 1: 500 dengan ketelitian memiliki ketelitian geometri peta kelas 1, hal ini karena horozontalnya tidak melebihi 0,2 meter dan ketelitian vertikalnya 0,2 meter, bahkan hasil evaluasi yang dilakukan oleh Cryderman et Al (2014) dengan mengganti sensor kamera dengan 21 Mega Pixels menghasilkan akurasi peta 1:200 dengan kontur 0,145 meter. Cryderman dan kawan-kawannya menggunakan tingkat kepercayaan 95 $\%$.

\subsection{Citra Drone versus Citra Satelit}

Biaya pemotretan dengan menggunakan drone kecil $(<13,6 \mathrm{~kg})$, lengkap dengan ground station dan peluncur, berkisar dari ratusan ribu rupiah sampai satu jutaan (Laliberte, 2009) dikutip oleh Shofiyanti (2011). Jika dibandingkan dengan citra satelit yang biasa dipergunakan untuk aplikasi inderaja di pemetaan bidang tanah, seperti Geoeye, Ikonos, Quickbird, Pleiades dan Worldview-2 maka citra drone ini relatif lebih murah. Tabel 5 berikut menunjukkan perbandingan deskripsi teknis dan biaya citra satelit dan drone.

Tabel 5. Deskripsi Teknis Dan Perkiraan Biaya Beberapa Citra Satelit Dan Drone

\begin{tabular}{|c|c|c|c|c|c|c|}
\hline \multirow[t]{2}{*}{ No } & \multirow[t]{2}{*}{ Jenis Citra } & \multicolumn{3}{|c|}{ Resolusi } & \multirow[t]{2}{*}{ Biaya } & \multirow[t]{2}{*}{ Keterangan } \\
\hline & & Spasial & Spektral & Temporal & & \\
\hline 1 & $\begin{array}{l}\text { Citra } \\
\text { Drone }\end{array}$ & $\begin{array}{c}0,15- \\
0,25 \mathrm{~m}\end{array}$ & $\begin{array}{c}\text { R, G } \\
\text { dan NIR }\end{array}$ & Fleksibel & Rp. 13.000 .000 & $\begin{array}{l}\text { Spesifikasi } \\
\text { setingkat } \\
\text { dengan Drone } \\
\text { DJI Phantom } 3 \\
\text { profesional }\end{array}$ \\
\hline 2 & Geoeye & $0.46 \mathrm{~m}$ & VNIR & 3 hari & $\begin{array}{l}\$ 25 \text { per } \mathrm{km}^{2} \text { untuk } \\
\text { perekaman baru } \\
\text { atau setara Rp. } \\
33.462 .500^{*} \text { ) }\end{array}$ & $\begin{array}{l}\text { Luas } \\
\text { Pemesanan } \\
\text { Minimum } 100 \\
\text { km² untuk } \\
\text { perekaman } \\
\text { baru }\end{array}$ \\
\hline 3 & Ikonos & $0.82 \mathrm{~m}$ & VNIR & 3 hari & $\begin{array}{l}\$ 25 \text { per } \mathrm{km}^{2} \text { untuk } \\
\text { perekaman baru } \\
\text { atau setara Rp. } \\
33.462 .500^{*} \text { ) }\end{array}$ & $\begin{array}{l}\text { Luas } \\
\text { Pemesanan } \\
\text { Minimum } 100 \\
\mathrm{~km}^{2} \text { untuk } \\
\text { perekaman } \\
\text { baru }\end{array}$ \\
\hline
\end{tabular}




\begin{tabular}{|c|c|c|c|c|c|c|}
\hline 4 & Quickbird & $0.65 \mathrm{~m}$ & VNIR & 1-3 hari & $\begin{array}{l}\$ 25 \text { per } \mathrm{km}^{2} \text { untuk } \\
\text { perekaman baru } \\
\text { atau setara Rp. } \\
33.462 .500^{*} \text { ) }\end{array}$ & $\begin{array}{l}\text { Luas } \\
\text { Pemesanan } \\
\text { Minimum } 100 \\
\mathrm{~km}^{2} \text { untuk } \\
\text { perekaman } \\
\text { baru }\end{array}$ \\
\hline 5 & $\begin{array}{c}\text { Worldview- } \\
2\end{array}$ & $0.46 \mathrm{~m}$ & VNIR & $\begin{array}{c}1.1-3.7 \\
\text { hari }\end{array}$ & $\begin{array}{l}\$ 25 \text { per } \mathrm{km}^{2} \text { untuk } \\
\text { perekaman baru } \\
\text { atau setara } \mathrm{Rp} . \\
33.462 .500^{*} \text { ) }\end{array}$ & $\begin{array}{l}\text { Luas } \\
\text { Pemesanan } \\
\text { Minimum } 100 \\
\mathrm{~km}^{2} \text { untuk } \\
\text { perekaman } \\
\text { baru }\end{array}$ \\
\hline 6 & Pleiades & $0,5 \mathrm{~m}$ & VNIR & 1 hari & $\begin{array}{l}\$ 17 \text { per } \mathrm{km}^{2} \text { untuk } \\
\text { perekaman baru } \\
\text { atau setara Rp. } \\
22.754 .500^{*} \text { ) }\end{array}$ & $\begin{array}{l}\text { Luas } \\
\text { Pemesanan } \\
\text { Minimum } 100 \\
\mathrm{~km}^{2} \text { untuk } \\
\text { perekaman } \\
\text { baru }\end{array}$ \\
\hline
\end{tabular}

Sumber: Lapan . 2017 (dengan olahan)

Catatan: *) Nilai Tukar Rupiyah Rp. 13.385,00 (Bank Mandiri, Update 23 Okt 17 08:28 WIB)

Perbandingan harga citra yang dihasilkan drone rata-rata lebih murah $61,16 \%$ (Rp. 20.462.500,-) jika pemesanan citra menggunakan luasan minimum pemesanan $100 \mathrm{~km} 2$, kecuali citra Pleiades relative lebih murah sekitar 42,87 \% (Rp. 9.754.500,-). Dengan demikian penggunaan drone sebahai wahana pemetaan bidang tanah sangat efisien biaya pemotretan dengan menggunakan drone.

\section{Penutup}

Pesawat tanpa awak (UAV) atau drone merupakan piranti yang berguna untuk berbagai aplikasi pemetaan bidang tanah, walaupun masih banyak kekurangan. Peralatan yang relatif murah dan mudah digunakan sangat diperlukan untuk percepatan pemetaan bidang tanah. penelitian ini menunjukkan bahwa penggunaan drone untuk percepatan pemetaan tanah adalah pilihan yang tepat karena hasil pemotretan drone punya resolusi spasial yang tinggi sehingga sesuai dengan aturan pemetaan bidang tanah dan harganya murah.
Disarankan dalam pemetaan bidang tanah dengan skala besar, seperti skala 1: 1000 atau lebih besar menggunakan drone minimal dengan sensor kamera 12 mega pixel agar ketelitian geometrik foto yang dihasilkan sesuai dengan harapan.

\section{Daftar Pustaka}

Adi, Anggoro Pratomo. et al. 2017. Pengujian Akurasi Dan Ketelitian Planimetrik Pada Pemetaan Bidang Tanah Pemukiman Skala Besar Menggunakan Wahana Unmanned Aerial Vehicle (UAV). Semarang: Jurnal Geodesi Undip. Volume 6, Nomor 1, Tahun 2017, ISSN:2337-845X.

Ahmad, Anuar. 2011. Digital Mapping Using Low Altitude UAV. Malaysia: Jurnal Pertanika J. Sci. \& Technol. Vol. 19, $51-58$.

Bahar, Emirul. 2016. Drone. (online) : emirul.staff.gunadarma.ac.id/Do wnloads/files/46041/DRONE.pdf

Bank Mandiri. 2017. Kurs Bank Mandiri. (online): 
http://www.bankmandiri.co.id/res ource/kurs.asp?row=2

Candiago, et.al. 2015. Evaluating Multispectral Images and Vegetation Indices for Precision Farming Applications from UAV Images. Switzerland: Jurnal Remote Sensing. 7(4), 40264047.

Cryderman, Chris. et Al. 2014. Evaluation Of Uav Photogrammetric Accuracy For Mapping And Earthworks Computations. Canada: Jurnal Geomatica, Vol. 68, No. 4, 2014 pp. 309 to 317.

Direktorat Jenderal Infrastruktur Keagrariaan Kementerian Agraria dan Tata Ruang/Badan Pertanahan Nasional. 2016. Petunjuk Teknis Pengukuran Dan Pemetaan Bidang Tanah Sistematik Lengkap. Jakarta : Direktorat Jenderal Infrastruktur.

DJI. 2015. Phantom 3 Professional Specs. (online): https://www.dji.com/phantom-3pro/info

Eisenbeiss, H, 2009. UAV Photogrammetry. Zurich: ETH Zurich.

Feng, et.al. 2015. UAV Remote Sensing for Urban Vegetation Mapping Using Random Forest and Texture Analysis. Switzerland: Jurnal remote sensing. Volume 7.

Fernández, et.al. 2016. Analysis of Landslide Evolution Affecting Olive Groves Using UAV and Photogrammetric Techniques. Switzerland: Jurnal remote sensing. 8, 837.

Hassan, et.al. 2011. Contextual Classification of Cropcam UAV High Resolution Images Using Frequency-Based Approach for Land Use/Land Cover Mapping. Malaysia: Symposium on Industrial Electronics and
Applications

September 25-28, 2011.

Kusmiarto. 2017. Problematika

Pembenahan Data Spasial

Bidang Tanah Di Kementerian

Agraria Dan Tata Ruang/Badan

Pertanahan Nasional. Prosiding

Seminar Nasional. ISBN: 602-

7894-35-0978-602-7894-35-8.

Dengan tema: : Problematika

Pertanahan dan Strategi

Penyelesaiannya. Di Universitas

Trisakti. Tanggal Oktober 2017.

Lapan. 2017. Data Citra Satelit. (online):

http://pusfatekgan.lapan.go.id/d ata/

Peraturan Kepala Badan Informasi Geospasial Nomor 15 Tahun 2014 Tentang Pedoman Teknis Ketelitian Peta Dasar.

Peraturan Menteri Negara

Agraria/Kepala Badan

Pertanahan Nasional No.3 tahun 1997 tentang Ketentuan Pelaksanaan Peraturan Pemerintah Nomor 24 Tahun 1997 Tentang Pendaftaran Tanah.

Peraturan Menteri Perhubungan No 90 Tahun 2015 tentang

Pengendalian Pengoprasian Pesawat Udara Tanpa Awak Di Ruang Udara Dilayani di Indonesia.

Permen ATR/BPN No. 25 Tahun 2015 Tentang Rencana Strategis Kementerian Agraria dan Tata Ruang/Badan Pertanahan Nasional.

Ramadhani, Yoniar Hufan. et Al. 2015. Pemetaan Pulau Kecil Dengan Pendekatan Berbasis Objek Menggunakan Data Unmanned Aerial Vehicle (Uav): Studi Kasus Di Pulau Pramuka, Kepulauan Seribu. Bogor: Jurnal Majalah IImiah Globë, Volume 17 No. 2 Desember 2015: 125134. 
Setyowati, Dewi Liesnoor. et al. 2014. Kartografi Dasar. Yogyakarta: Penerbit Ombak.

Shofiyanti, Rizatus. 2011. Teknologi Pesawat Tanpa Awak Untuk Pemetaan Dan Pemantauan Tanaman Dan Lahan Pertanian. Bogor: Jurnal Informatika Pertanian, Vol. 20 No.2, Desember 2011 : 58 - 64 .

Wulan, Theresia Retno. et al. 2016. Uji Akurasi Data UAV (Unmanned Aerial Vehicle) Di Kawasan Pantai Pelangi, Parangtritis,
Kretek, Kabupaten Bantul. Prosiding Seminar Nasional Kelautan 2016. Di Universitas Trunojoyo Madura, tanggal 27 Juli 2016.

Zarco, \& Pablo J., et.al. 2014. Tree height quantification using very high resolution imagery acquired from an unmanned aerial vehicle (UAV) and automatic 3D photo-reconstruction methods. European journal of agronomy, 89-99. 